Judith Thissen*

\title{
Filmgeschiedenis tussen cultuur en economie
}

Dit themanummer gaat over het filmbedrijf als bedrijf: over ondernemers en ondernemerschap, over concurrentie, marktkansen, verschuivingen in vraag en aanbod, over consumenten en de markt als sociaal proces. Film wordt nadrukkelijk benaderd als een product dat verkocht en gekocht wordt in de context van een kapitalistische economie. Gelet op de geschiedenis van het medium lijkt dit een voor de hand liggende insteek, maar dat is allerminst het geval. In 1974 verbaasde de Groningse hoogleraar Economische en Sociale Geschiedenis Henri Baudet zich over het feit dat 'praktisch alle filmhistorici wijzen op de economische betekenis van de filmindustrie', maar dat zij tegelijkertijd aan het economische gezichtspunt slechts marginaal aandacht besteedden:

'Alle vermaarde filmgeschiedenissen zijn zonder uitzondering uit een kunsthistorisch, technologisch of biografisch gezichtspunt geschreven. Er zijn weliswaar publikaties verschenen over verschillende economische aspecten van de filmindustrie, maar dit zijn veeleer sterk specialistische detailstudies, die zich nimmer te buiten gaan aan de geschiedenis van de film.' ${ }^{\text {I }}$

Sindsdien is er weinig veranderd, zowel in Nederland als internationaal. ${ }^{2}$ Economen die zich bezighouden met filmgeschiedenis zijn nog steeds schaars en werken doorgaans in de marge van hun discipline. We stuiten op steeds dezelfde namen: Gerben Bakker, Douglas Gomery, Michael Pokorny, John Sedgwick en Arthur de Vany. Historici op hun beurt dragen nauwelijks bij aan de ontwikkeling van cultural economics waardoor deze jonge discipline een zeer presentistische oriëntatie heeft gekregen. ${ }^{3}$ Datzelfde geldt voor het onderzoek naar creatieve industrieën en cultureel ondernemerschap, dat vooral plaatsvindt binnen sociale wetenschappen. ${ }^{4}$ De filmgeschiedschrijving tot slot is inmiddels zo sterk georiënteerd op de culturalistische variant van cultural studies dat er slechts zelden serieuze aandacht wordt

Judith Thissen is sinds 200I als universitair docent verbonden aan het Departement Media- en Cultuurwetenschappen van de Universiteit Utrecht. Haar onderzoeksinteresse ligt op het snijvlak van media, cultuur en politiek, met bijzondere aandacht voor vraagstukken van sociale ongelijkheid. Ze publiceerde o.a. over vroege Amerikaanse bioscoopcultuur, Jiddisch theater, joods ondernemerschap in de filmindustrie en Nederlandse filmgeschiedschrijving. In het kader van het Nwo-programma Transformaties in Kunst en Cultuur werkt ze aan een onderzoek naar commercialiseringsprocessen binnen het culturele veld. 
geschonken aan de economische context of de relatie tussen cultuur en economie. Een zekere aversie tegen alles wat 'riekt naar commercie' kenmerkt bovendien het vakgebied in brede zin. Filmwetenschappers houden zich traditiegetrouw bezig met de stilistische, narratieve en culturele dimensies van het medium. Vanuit een wetenschappelijk oogpunt blijft dit opmerkelijk, omdat commercie al vanaf het prille begin onlosmakelijk verbonden is met film en bioscoop.

Zowel in Europa als in Amerika waren de pioniers van de cinematografie in de eerste plaats ondernemers die op zoek waren naar nieuwe bronnen van inkomsten. Naast kapitaalkrachtige industriëlen als Edison en de gebroeders Lumière, werd het vroege filmbedrijf bevolkt door talloze kleine zelfstandigen die veelal in de marges van het gevestigde bedrijfsleven opereerden en niet gericht waren op economische expansie, maar simpelweg probeerden te overleven in een context van hevige concurrentie. De grote jongens binnen de nieuwe bedrijfstak werden al in I9I4 door Robert Grau opgenomen in het pantheon van het Theatre of Science. 5 De sappelaars en 'mislukkelingen' werden pas in de jaren tachtig en negentig ontdekt in het kader van de New Film History. Een van de verdiensten van die New Film History was de hernieuwde belangstelling voor de technologische geschiedenis van de film. Dat leidde in de beginfase tot een aantal studies waarin ook plaats werd ingeruimd voor grondige analyses van economische ontwikkelingen, zowel op microniveau (personen, bedrijven) als mesoniveau (bedrijfstak). Innovatietheorieën werden ingezet om een brug te slaan tussen de technologische, economische en culturele aspecten van het onderzoek. Een schoolvoorbeeld van deze geïntegreerde aanpak is de studie van Karel Dibbets over de introductie van de geluidsfilm in Nederland. Juist door technologische innovatie niet te beschouwen als een zuiver economisch verschijnsel, maar tevens als een maatschappelijk proces, weet hij bedrijfsgeschiedenis en cultuurgeschiedenis op een overtuigende manier te combineren. Het boek belandde al snel in de ramsj, maar verdient het alsnog tot een klassieker van de Nederlandse filmgeschiedenis uit te groeien. ${ }^{6}$ Een ander onderzoek dat in dit kader niet onvermeld mag blijven is de studie van Ivo Blom over de activiteiten van bioscoopexploitant en filmverhuurder Jean Desmet. Voor iedereen die iets weten wil over het vroege filmbedrijf in Nederland is dit verplichte kost. Gezien het onderwerp is het echter opmerkelijk dat Blom niet eenduidig insteekt vanuit een economisch perspectief. Blom analyseert Desmets overgeleverde bedrijfsarchief vanuit het concept 'collectie', dat hij weliswaar sociaal en historisch contextualiseert, maar dat desalniettemin sterk gelieerd blijft met de kunstgeschiedenis - Bloms oorspronkelijke discipline.7

De vraag blijft waarom de economische filmgeschiedschrijving zo weinig voet aan de grond gekregen heeft in Nederland, waar de sociaaleconomische geschiedschrijving immers een lange en solide traditie kent. Achteraf gezien lijken drie parallelle ontwikkelingen hieraan debet. Allereerst zien we in de jaren negentig de teloorgang van het ideaal van de geïntegreerde histoire totale. Dit ging gepaard met een hernieuwde verkokering van de geschiedschrijving, waardoor zowel het onderzoek als het universitaire onderwijs uiteen vielen in allerlei subdisciplines: cultuur- 
geschiedenis, economische geschiedenis, stadsgeschiedenis, vrouwengeschiedenis, enzovoort. In dat proces raakten de filmhistorici automatisch opgesloten in hun eigen 'hokje' en verloren ze het contact met de algemene geschiedwetenschap. Tegelijkertijd maakte in Nederland de filmwetenschap als universitaire discipline een enorme sprong voorwaarts dankzij de instelling van de leerstoelen film- en televisiewetenschap in Amsterdam en Utrecht. Deze sprong voorwaarts had echter ook een keerzijde want zijn oriëntatie was nadrukkelijk internationaal en het opbouwen van een constructieve samenwerking met het Nederlandse geschiedwetenschappelijke veld bleef zo goed als achterwege, zeker waar het de sociaaleconomische geschiedenis betrof. Dit effect werd versterkt door het feit dat eind jaren negentig de New Film History al weer over haar hoogtepunt heen was. Nieuwe media als het internet en mobiele telefonie trokken massaal de belangstelling van jonge en oudere wetenschappers. Met name het onderzoek naar technologische en economische aspecten van de filmgeschiedenis verloor hierdoor in snel tempo terrein. Voor wie zich nog wel bezighield met filmhistorisch onderzoek waren de nieuwe toverwoorden cultural studies en cultural analysis. Of zoals David Bordwell het wat cynisch stelde in I996: 'the word "culture" has become to I990s academe what Toyotas have become for the automobile market' ${ }^{8}$

De programmatische artikelen die de nieuwe hoogleraren Thomas Elsaesser en William Uricchio indertijd publiceerden in de voorlopers van het Tijdschrift voor Mediageschiedenis maken de afstand tot sociaaleconomisch georiënteerd onderzoek duidelijk. Elsaesser benadrukte in 'What might we mean by media history' (GBG Nieuws, I994) weliswaar het commodity-karakter van films, maar liet weinig ruimte over voor een materialistische geschiedschrijving. Uiteindelijk blijft voor hem de filmtekst het object van de filmgeschiedenis:

'For despite the evidence accumulated by the new film history that the cinema, or at any rate, the American cinema, has behaved like any other capitalist industry this century, such knowledge is insufficient for approaching the social and historical role of the cinema. Industrial and technological analysis, and even the history of spectatorship and consumption may take one a long way away from the films. But they also have eventually to bring one back to the films: all this economic and discursive activity would not exist without spectators hungry for stories and images, for sights and sounds arranged, combined and organized in particular ways. There is thus a hermeneutic circle (or spiral) whereby film history, as it leads us away from the film text, moves us closer to it, but not to its material or commodity existence. Instead, it is the film text's existence in and evidence of an individual or cultural imaginary (its aesthetics, its forms, its coherences and breaks, its ideologies and utopian dimensions) that demands our attention.' 9

Uricchio zette zich in het artikel 'Filmgeschiedenis in het fin de siècle' (Jaarboek Mediageschiedenis, I997) juist af tegen 'de neiging filmgeschiedenis eerst en vooral 
te zien als een tekstueel probleem'. In plaats daarvan wil hij filmgeschiedenis primair opvatten als 'een complex van cultureel begrensde praktijken' ${ }^{\text {Io }}$ Voor Uricchio zijn de historische en sociale context van cruciaal belang. In zijn visie op de toekomst van de mediageschiedschrijving in Nederland worden echter de vele manieren om filmgeschiedschrijving te beoefenen gecomprimeerd tot een brede cultuurhistorische aanpak waarbinnen de bestudering van de economische dynamiek van filmcultuur op zijn best een secundaire plaats inneemt.

Door de hierboven geschetste combinatie van interne en externe factoren is de culturele insteek sinds de jaren negentig dominant binnen het filmhistorische onderzoek in Nederland, geheel in lijn met de internationale trend. Tegelijkertijd zien we de laatste jaren zowel in Nederland als daarbuiten in sommige delen van het veld een verschuiving in de richting van de sociale geschiedschrijving. Filmhistorici krijgen meer oog voor de sociale dynamiek van lokale en nationale filmculturen, mede dankzij de groeiende interesse in vertoningscontexten en historisch receptieonderzoek. ${ }^{\text {II }}$ Via deze achterdeur komen ook de ondernemers en bedrijven die de films aan de man brachten opnieuw in het vizier. Binnen de New Cinema History, een sociaalhistorisch subveld dat inmiddels is uitgegroeid tot een volwaardige tak van filmstudies, wordt aan ondernemers zelfs een centrale rol toegekend in het maatschappelijk proces dat leidt tot de formatie van specifieke filmculturen en filmconsumptiepatronen. ${ }^{\text {I2 }}$ Probleem is echter dat er ook in dit type onderzoek weinig aandacht is voor film als handelswaar. Bovendien zijn ondernemers nog steeds nauwelijks zichtbaar als ondernemer, omdat doorgaans gekozen wordt voor een benadering waarin ondernemerspraktijken en -strategieën geanalyseerd worden in termen van culturele bemiddeling. ${ }^{33}$ Dat bioscoopexploitanten en distributeurs fungeerden als culturele bemiddelaars zal ik niet ontkennen en evenmin het belang van deze insteek. Het punt is dat de economische dimensies van het filmbedrijf vooralsnog te zeer een blinde vlek zijn gebleven binnen de New Cinema History. We hopen met dit themanummer te laten zien waarom het zin heeft daarin verandering te brengen. Een beter inzicht in het economisch handelen van bedrijven en ondernemers in de filmsector werpt immers ook nieuw licht op zaken als de bestedingspatronen en smaakvoorkeuren van het publiek. Daarmee komen we een stapje dichter bij een filmgeschiedenis waarvan de wetenschappelijke relevantie ook buiten het eigen vakgebied duidelijk kan worden gemaakt - iets waar Richard Maltby al eerder nadrukkelijk voor pleitte in TMG. ${ }^{\mathrm{I}}{ }^{4}$

De centrale insteek van dit themanummer is 'de markt', beschouwd vanuit het perspectief van de bedrijfstak. Zoals de meeste bijdragen laten zien is de markt niet alleen een commerciële ruimte waarin prijsafspraken worden gemaakt tussen aanbieders en afnemers, maar ook een sociaal fenomeen waarin processen van betekenisgeving een belangrijke rol spelen. Net als in andere creatieve industrieën hebben sociaal-culturele factoren grote invloed op het reilen en zeilen van het filmbedrijf en juist deze verwevenheid van economie en cultuur maken de markt tot een interessant vertrekpunt voor een geschiedenis van film als consumptiegoed. 
In het openingsartikel gaat Gerben Bakker in op de structurele economische eigenschappen van de filmindustrie en de effecten daarvan op de ontwikkeling van de bedrijfstak. Hij zoekt de verklaring voor de dominante marktpositie van Hollywood in de kwaliteitsrace die zich tijdens de jaren tien voltrok binnen de Amerikaanse filmindustrie. Mede door investeringen van beleggers die tegenwoordig venture capitalists worden genoemd, stegen de productiebudgetten in korte tijd explosief. Europese producenten konden nauwelijks deelnemen aan deze kwaliteitsrace omdat tijdens de Eerste Wereldoorlog (durf)kapitaal schaars was en hun Europese afzetmarkt uiteengevallen was in kleine nationale markten. Tijdens het Interbellum werd het steeds moeilijker voor Europese filmproducenten om te concurreren met de Hollywoodstudio's, ondanks overheidshulp die ook toen al doorgaans op basis van culturele argumenten werd verstrekt. In deze situatie is sindsdien weinig verandering gekomen.

Clara Pafort-Overduin, John Sedgwick en Jaap Boter benaderen de vraag waarom het Nederlandse bioscooppark beduidend kleiner was dan dat in andere westerse landen in eerste instantie vanuit een zuiver economisch perspectief, net als Bakker. Op basis van een uitgebreide dataset onderzoeken ze in hoeverre de distributie- en vertoningspraktijken in Nederland afweken van het Angelsaksische run-zoneclearance-model. Het blijkt dat er geen fundamentele verschillen waren voor zover het de jaren dertig betrof, de periode waarop hun onderzoek zich concentreert. Wel komen zij tot de opmerkelijke ontdekking dat Nederlanders tijdens de crisis hetzelfde percentage van hun consumptiebudget aan bioscoopbezoek besteedden als de Engelsen, maar dat ze met dat budget veel minder vaak naar de bioscoop konden gaan omdat hier de toegangsprijzen veel hoger lagen dan in Groot-Brittannië. In het tweede deel van de bijdrage maken (macro)economische analyses plaats voor een statistische toetsing van een aantal sociaalhistorische theses met betrekking tot de achterblijvende belangstelling voor de bioscoop in Nederland. Pafort-Overduin et al. pakken de discussie op over de effecten van verzuiling en klasse en concluderen dat de aanwezigheid van protestanten een negatieve invloed had op de omvang van het lokale bioscooppark, terwijl de aanwezigheid van inwoners die vermogensbelasting betaalden juist positief doorwerkte. De vraag blijft of deze constellatie specifiek is voor de jaren dertig of dat dezelfde economische en sociaal-culturele factoren ook al een rol speelden (wellicht zelfs sterker) in de eerste decennia van het bioscoopbedrijf en daarmee al veel vroeger Nederlandse exploitanten op een achterstand zetten ten opzichte van hun collega's in de omringende landen.

De invloed van de sociale geografie van het publiek op de dynamiek van de markt is evenals de relatie tussen Hollywood en de Europese filmindustrie een terugkerend onderwerp in dit themanummer. In de twee Belgische bijdragen worden beide aspecten in relatie tot elkaar geanalyseerd. Het artikel van Lies Van de Vijver en Daniël Biltereyst over de Gentse bioscoopmarkt in de jaren dertig - een periode die klaarblijkelijk sterk in de belangstelling staat - laat zien dat de hegemonie van Hollywood verschillende vormen aannam en de Europese filmproducenten wel degelijk konden rekenen op een trouw publiek. De top- 5 lijsten in de periode 
I933-I936 werden gedomineerd door Europese titels. Het betrof met name producties uit Duitsland en Frankrijk, maar ook films van eigen bodem zoals DE WITTE (België, I934) en ALlEEN VOOR U (België, I935) deden het uitstekend. Het onderzoek naar de Gentse bioscoopcultuur maakt bovendien duidelijk dat binnen één stad de verschillen zeer groot konden zijn. In Gent trokken de duurdere zalen in het centrum met een overwegend Europees repertoire een breed publiek waaronder de Franstalige elite. Alleen in de Majestic die in handen was van MGM domineerden Amerikaanse premièrefilms het programma. De buurtbioscopen daarentegen trokken hoofdzakelijk een arbeiderspubliek dat een grote voorkeur toonde voor Duitse, Oostenrijkse en Amerikaanse films. Een deel van deze Amerikaanse producties draaide alleen in de volkswijken aan de rand van de stad. Dit betekent dat in Gent de distributie deels afweek van het klassieke Angelsaksische systeem waarbij de films eerst in het centrum in roulatie gaan en vervolgens in de periferie getoond worden. Wel zien we de traditionele tegenstelling tussen enerzijds dure, luxueuze centrumzalen die eigendom zijn van naamloze vennootschappen en anderzijds goedkope wijktheaters die veelal multifunctioneel van opzet waren en gerund werden door kleine zelfstandige ondernemers.

Net als in Gent was ook in het naoorlogse Antwerpen de positie van de Hollywood-majors minder sterk dan de bestaande literatuur doet vermoeden. Kathleen Lotze en Philippe Meers reconstrueerden het Antwerpse bioscooplandschap in de periode I950-I975 waarbij ze geografische data combineerden met een analyse van de programmeringpraktijken en het publieke discours over specifieke zalen en patronen van bioscoopbezoek. Een vijftigtal bioscopen was in de stad actief waarbij vanaf begin jaren zestig geen enkele meer in het bezit was van de Hollywoodmajors. Centraal in hun analyse staat het Rex-concern van Georges Heylen, die het merendeel van de bioscopen in de Antwerpse binnenstad controleerde en ook daarbuiten zijn invloed uitoefende als programmeur. Uit de analyse van de filmprogrammering blijkt dat Heylen een zeer breed en uitgekiend programmeringsbeleid voerde waarmee hij elk van zijn zalen een eigen karakter gaf, dat ook als zodanig door het publiek werd herkend. Net als in Gent was er ook hier een duidelijke hiërarchie tussen de centrum-, rand- en wijkzalen. Vanuit een oogpunt van winstmaximalisering werd het run-zone-clearance-systeem systematisch door Heylen toegepast. Het patroon werd alleen doorbroken toen Heylen rond I970 in conflict kwam met de grote Amerikaanse distributeurs en deze vervolgens besloten om het Rex-concern niet meer van films te voorzien. Amerikaanse kaskrakers ging in première in de kleine theaters in de periferie, terwijl Heylen de doeken van zijn filmpaleizen en tweedeweekszalen vulde met Europese films. Dankzij zijn gedegen kennis van de Antwerpse markt en de goodwill van het publiek overleefde het bedrijf de Amerikaanse boycot. Na ruim twee jaar werd het conflict grotendeels in Heylens voordeel beslecht.

De casus van het Rex-concern in Antwerpen maakt duidelijk dat Hollywood ondanks zijn dominante positie afhankelijk bleef van allianties met lokale spelers en niet unilateraal de markt kon dicteren. Dat is nog steeds het geval, zoals Miriam van 
de Kamp laat zien in haar artikel over de recente distributiepraktijken van de majors in Nederland. Vanwege een schaarste aan bioscoopdoeken (een constante in de Nederlandse filmgeschiedenis) hebben Nederlandse bioscoopexploitanten een sterker onderhandelingspositie dan bijvoorbeeld hun Belgische collega's. Hierdoor kunnen ze gunstige huurwaarden afdwingen en dat vertaalt zich in lage marges voor de Amerikaanse distributeurs. Het is een interessante paradox: de majors zijn de belangrijkste aanbieders van films in Nederland, maar ze verdienen weinig aan deze afzetmarkt. Na een algemene schets van de marktcondities en de wijze waarop de regiokantoren van multimediaconglomeraten als Sony, Disney en Warner Bros. opereren, zoomt Van de Kamp specifiek in op de distributie van lokaal geproduceerde films. Hieruit wordt duidelijk dat een combinatie van externe factoren (Europese kartelwetgeving, Nederlands overheidsbeleid) en interne omstandigheden (eigenzinnig beleid van lokale directeuren) geleid heeft tot een opmars van Nederlandse speelfilms, die mede dankzij de majors het Nederlandse publiek bereikten. Hun rol op deze nichemarkt blijft echter beperkt omdat de distributie van Nederlandse films niet uitgroeide tot een kernactiviteit.

Een heel andere blik op de recente bloeiperiode van de Nederlandse speelfilm biedt het artikel van Sigrid Hemels. Zij analyseert de Nederlandse filmmarkt vanuit een fiscaal-economisch perspectief waarbij ze de complexe belastingmaatregelen waarmee de Nederlandse overheid in de periode 1998-2007 de filmsector probeerde te stimuleren, helder uitlegt voor niet-fiscalisten en vanuit haar eigen vakgebied kritisch evalueert. Met name door middel van commanditaire vennootschappen (filmcv's) stroomden eind jaren negentig honderden miljoenen naar de filmindustrie - die anders via de belastingdienst in de schatkist terecht waren gekomen. De stimuleringsmaatregelen zorgden voor een escalatie in productiebudgetten en voor een professionaliseringsslag. Deze ontwikkeling vertoont overeenkomsten met de kwaliteitssprong die de Amerikaanse filmindustrie maakte in de jaren tien, zij het op kleinere schaal. Van een daadwerkelijke betrokkenheid van beleggers met de filmindustrie was echter geen sprake, aldus Hemels. Het ging puur om de centen. Toen na het afblazen van het prestigieuze filmproject SOLDAAT VAN ORANJE 2 duidelijk werd dat er met film-cv's grote verliezen geleden konden worden en de overheid bovendien de veel te dure subsidiemaatregel aanpaste en vervolgens afschafte, trokken particuliere investeerders zich weer terug uit de filmsector.

Toch weten filmmakers en onafhankelijke producenten telkens weer kapitaal te vinden om hun projecten te realiseren. Steeds vaker komt dit geld uit onverwachte hoek: uit het zakelijke circuit rondom de festivalwereld. Marijke de Valck brengt de groeiende rol van de coproductiemarkten en andere commerciële activiteiten die in het kader van internationale filmfestivals plaatsvinden onder de aandacht. Trendsetter op dit vlak was de CineMart van het International Film Festival Rotterdam, die sinds I983 wordt georganiseerd om de financiering van art-house-films te faciliteren. Aan de hand van deze casus laat De Valck zien hoe de onafhankelijke filmproductie zich in het laatste decennium in hoog tempo heeft geprofessionaliseerd. Een van de gevolgen hiervan is dat productiebudgetten sterk gestegen zijn en de economische 
aspecten zwaarder zijn gaan wegen bij de selectie van filmprojecten voor internationale coproductie. Omdat artistieke risico's om financiële redenen vermeden worden, dreigt het gevaar dat deze kwaliteitsrace binnen de onafhankelijke filmproductie resulteert in een verschraling van de diversiteit van het aanbod. Rest het filmpubliek straks alleen nog de keuze tussen Hollywoodfilms en hoogwaardige artistieke eenheidsworsten van het merk kunstfilm zoals de voorvechters van een puur culturele benadering van de film vrezen? De Valck is minder pessimistisch en benadrukt dat persoonlijke stijl en authenticiteit nog steeds hoog in het vaandel staan bij de organisatoren van de CineMart. Tegelijkertijd maakt haar analyse meer dan duidelijk dat er sprake is van een vérgaande commercialisering van de kunstfilm.

De laatste bijdrage aan deze bundel gaat weer een stapje terug in de tijd. Thunnis van Oort inventariseert hoe de markt voor filmtijdschriften zich ontwikkelde in Nederland in de eerste helft van de twintigste eeuw, waarbij hij zich vooral richt op bladen voor het grote publiek. In de meeste landen werden fanmagazines bij uitstek gezien als een middel om bioscoopbezoek te stimuleren. Was dat ook zo in Nederland, of was er wederom sprake van een moeizame nichemarkt, ditmaal binnen het uitgeverijbedrij? Dit laatste lijkt het geval, al blijft het lastig om conclusies te trekken want concrete cijfers over oplages, omzetten en winsten ontbreken. Alleen de ondernemende journalist Pier Westerbaan wist met het amusementsblad Cinema en theater ruim twintig jaar een stabiel lezerspubliek aan zich te binden. Vanuit commercieel perspectief waren de gespecialiseerde bladen met een meer cinefiele oriëntatie, zoals De Filmliga en het katholieke Filmfront, slechts marginale tijdschriften. Als redacteur, uitgever en drukker was Westerbaan een spil in het vooroorlogse filmbedrijf, omdat hij niet alleen het grote publiek maar ook het professionele filmveld bediende. Hij gaf naast Cinema en theater het vakblad Nieuw Weekblad voor de Cinematografie uit (waarvan hij tevens hoofdredacteur was) en drukte vele lokale bioscoopprogramma's, bijvoorbeeld het wekelijkse Rembrandt Nieuws. Na de Tweede Wereldoorlog - een bloeiperiode voor het bioscoopbedrijf ging het bergafwaarts met de filmbladenmarkt. Er werden weliswaar veel nieuwe titels gelanceerd, maar het merendeel van deze tijdschriften was slechts een kort leven beschoren. Niemand wist de succesformule van Westerbaan nieuw leven in te blazen.

Een sleutelfiguur als Westerbaan verdient uitgebreid onderzoek. Hetzelfde geldt voor andere ondernemers, bedrijven en marktontwikkelingen die in dit nummer aan bod komen. Veel aspecten van het Nederlandse en Belgische filmbedrijf zijn volledig buiten beeld gebleven. Zeker voor de recente periode is er sprake van een bijna onontgonnen terrein. De focus op het filmbedrijf en de markt die voor dit themanummer is gekozen kent bovendien zijn beperkingen. Zo komen macroeconomische perspectieven niet meer dan zijdelings in beeld terwijl de recessie ten gevolge van de kredietcrisis ons met de neus drukt op het feit dat periodes van laagconjunctuur ook in het culturele veld grote verschuivingen teweeg kunnen brengen. Hetzelfde gaat natuurlijk op voor periodes van hoogconjunctuur. In die zin behan- 
delt dit themanummer slechts één dimensie van de economische geschiedenis van de film. Kortom, er is nog genoeg werk aan de winkel.

\section{Noten}

I H. Baudet e.a., 'Consumenten en Innovaties (II): Een nieuwe benadering van historisch consumentengedrag', in: Maandschrift Economie, aug/sept I974, p. 6r3. Terecht werd door Baudet en zijn medeauteurs een uitzondering gemaakt voor Der Film als Ware (I945) van Peter Bächlin. Bächlin verankerde zijn marxistische analyse van film als handelswaar en massaproduct namelijk in een degelijke historische analyse van de economische ontwikkeling van filmproductie, -distributie en -vertoning in Amerika en Europa in de eerste helft van de twintigste eeuw.

2 Zie J. Sedgwick \& M. Pokorny (red.), An Economic History of Film, Londen 2005, p. 2.

3 Zie bijv. P. du Gay \& M. Pryke (red.), Cultural Economy: Cultural Analysis and Commercial Life, Londen 2002.

4 Een noemenswaardige uitzondering is het Nwo-programma Places and their culture: The evolution of Dutch cultural industries from an international perspective, 1600-2000 onder leiding van R.C. Kloosterman en M.R. Prak waarin historici en sociaal geografen samen onderzoek doen naar de opkomst en ontwikkeling van creatieve industrieën in Nederland.

5 R. Grau, The theatre of science: A volume of progress and achievement in the motion picture industry, New York igi4.

6 K. Dibbets, Sprekende films: De komst van de geluidsfilm in Nederland, 1928-1933, Amsterdam I992. Het boek is te downloaden van de website van K. Dibbets (www.xs4all.nl/ kd).

7 I. Blom, Pionierswerk. Jean Desmet en de vroege Nederlandse filmhandel en bioscoopexploitatie (diss. Amsterdam UvA), 2000. Handelseditie: Jean Desmet and the Early Dutch Film Trade, Amsterdam, 2003.

8 D. Bordwell, 'Contemporary Film Studies and the Vicissitudes of Grand Theory,' in: D. Bordwell \& N. Carroll (ed.), Post Theory: Reconstructing Film Studies, Madison Wisconsin I996, p. 9.

9 T. Elsaesser, 'What might we mean by media history', in: GBG Nieuws 28, I994, p. 22.

Io W. Uricchio, 'Filmgeschiedenis in het fin de siècle', in: Jaarboek Mediageschiedenis, 8, I997, p. I3.

II Een aantal Amerikaanse studies uit de jaren zeventig en tachtig kunnen daarbij als inspiratiebron dienen. Ik denk daarbij specifiek aan G. Jowett, Film: The Democratic Art, Boston I976; K. Peiss, Cheap Amusements: Working Women and Leisure in Turn-of-the Century New York, Philadelphia I986; R. Rosenzweig, Eight Hours for What We Will: Workers and Leisure in an Industrial City, 1870-1920, Cambridge I983; R. Sklar, Movie-Made America: A Cultural History of American Movies, New York I975. Voor een uitgebreide positionering van deze publicaties binnen het filmhistorische veld, zie J. Thissen, Moyshe Goes to the Movies: Jewish Immigrants, Popular Entertainment, and Ethnic Identity in New York City (1880-1914) (diss. Utrecht), 200I, p. 2-7.

I2 Zie bijv. D. Biltereyst, R. Maltby \& P. Meers (ed.), New Cinema History: Approaches and Case Studies, Cambridge, in druk.

I3 Een Nederlands voorbeeld van deze aanpak is T. van Oort, Film en het moderne Leven in Limburg: Het bioscoopwezen tussen commercie en katholieke cultuurpolitiek (1909-1929), Hilversum 2007. Zie ook Richard Maltby, 'On the prospect of Writing Cinema History From Below', in: Tijdschrift voor Mediageschiedenis 9/2006-2, p. 91.

I4 Maltby, 'On the prospect of Writing Cinema History From Below'. 